\title{
Reseña de Salvi, Valentina, De vencedores a víctimas. Memorias militares sobre el pasado reciente en la Argentina. Buenos Aires, Biblos, 2012, 229 págs.
}

\author{
MARÍA CECILIA TONON (UNL) \\ Centro de Estudios Sociales Interdisciplinarios del Litoral \\ Facultad de Humanidades y Ciencias \\ Universidad Nacional del Litoral \\ Santa Fe, Argentina \\ tononcec@,hotmail.com
}

Valentina Salvi es la autora del texto De vencedores a victimas. Memorias militares sobre el pasado reciente en la Argentina, en el que presenta una mirada caleidoscópica de una generación de oficiales del Ejército Argentino vinculada con la denominada "lucha contra la subversión". Estas diferentes visiones que se despliegan, reflejan los sentidos impregnados en este grupo de oficiales, de sus allegados, y de aquellos civiles que salvaguardan la memoria de estos militares comprometidos en la última dictadura.

El objeto de estudio concuerda con lo que ha venido investigando la autora en sus últimos trabajos, y el presente libro parece reunir estos diversos aportes. Así, en esta producción hay un predominio del discurso, resucitado una y otra vez en las diferentes memorias, cuya producción, apropiación y transmisión no son inmunes a los cambios. El planteamiento principal del libro, entonces, apunta a señalar estas alteraciones en torno a las memorias: la institucional o pública que mantiene el ejército, la de los oficiales retirados que han estado implicados en los procesos de represión, la de los familiares de los oficiales muertos en acción e identificados con el lema Memoria Completa y la de los oficiales actualmente en actividad. En palabras de la propia investigadora, se trata de "analiza[r] las memorias castrenses sobre el pasado reciente en torno a sus conflictos-diferencias y sus continuidades-rupturas.” (pág.15) Esto conforma el elemento más significativo y novedoso del planteo de Salvi, porque lo que pone en discusión e intenta contrastar es una imagen monolítica que se ha tenido tradicionalmente del discurso de estos cuadros del ejército, que por el contrario ha de verse como una pluralidad de discursos, con sentidos diferentes, contrapuestos y en permanente redefinición.

A partir de esta tesis central, es posible identificar un conjunto de problemas y de tópicos de los que se ocupa convenientemente el trabajo. Por un lado, cabe mencionar el análisis de las representaciones y conmemoraciones de los oficiales muertos durante la década de los setenta. Por otro lado, el tratamiento del devenir memorialístico de los sujetos de estudio, respecto de los distintos posicionamientos que se han construido entre el período de la transición democrática -a comienzos de los ochenta- hasta el inicio de los juicios por crímenes de lesa humanidad -durante el primer gobierno de Néstor Kirchner- en relación a la memoria institucional del ejército y a las actitudes de la clase dirigente postdictatorial y de la sociedad en general. En este sentido, vale la pena mencionar la indagación que la autora hace respecto de la filiaciones que estos grupos entablan "no sólo con el pasado que pretenden rememorar [y en este caso, cómo lo hacen, y cómo van alterando su sentido] sino con el horizonte de futuro al cual se dirigen sus legados" (pág.17). De esta forma, se intenta desentrañar las relaciones entre 
memoria, identidad e integridad presentes en estas generaciones de oficiales, su transmisión a las generaciones futuras, y su impacto en la sociedad civil.

Para desarrollar estos tópicos, Salvi parte de algunas consideraciones fundamentales que conforman las preguntas de investigación de cada una de las partes que componen el libro, y que por su significatividad como guías de la propuesta, nos permitimos recuperarlas aquí:

- Respecto de la memoria institucional del ejército sobre la represión ilegal: ¿cuáles son los sentidos y verdades que pugnan por ser legitimados en cada uno de los ciclos de deconstrucción y reconstrucción? ¿Cuáles son los agentes encargados de establecer y difundir la memoria oficial y qué soportes utilizan para ello? ¿Con cuáles otros actores sociales se enfrenta y vincula la memoria del ejército?

- Sobre las memorias y prácticas conmemorativas de los oficiales retirados el ejército: ¿qué eventos o hechos se priorizan o se ocultan en los "actos de homenaje" y la memoria de la "lucha contra la subversión”? ¿Qué retóricas y performances se movilizan y cuáles caen en desuso? ¿Cuáles son los personajes o se convierten en portavoces autorizados y quienes en interlocutores legítimos?

- Sobre el acto de recordar por parte de los oficiales retirados: ¿de qué pueden ser reveladores los relatos en primera persona? ¿Cómo es la relación entre los oficiales retirados y los cuadros en actividad?

- Para la generación transmisora de memoria: ¿qué sentidos buscan ser preservados y cuáles efectivamente los son?

Estas problemáticas son abordadas a través de una metodología cualitativa, desde una perspectiva de la historia reciente, con la apelación a propuestas propias de la sociología, la antropología y el análisis del discurso. Sobresale un fuerte acento puesto en los actores: sus pensamientos, sus sentimientos, sus dichos, sus silencios, y, de esta forma, el recurso a técnicas necesarias para tratarlos. Para la recolección de información, el reporte da cuenta de un trabajo de campo realizado a partir de entrevistas informales y semiestructuradas y focus group con oficiales retirados y en actividad, de observaciones de actos conmemorativos privados y públicos, y la recopilación documental a partir del análisis de fuentes secundarias como cadenas de mails, revistas, libros, páginas web, periódicos, discursos, panfletos, comunicaciones, manuales, documentos oficiales, entre otras documentaciones.

Este importante trabajo heurístico realizado por la autora va de la mano de una considerable preocupación por la interpretación de los datos obtenidos, que sobresale en el trabajo en aspectos tales como la periodización seleccionada (que no sigue un orden cronológico, sino más bien lógico-discursivo) y la organización general de la obra. Esta impronta hermenéutica es deudora de una matriz teórica que tiene a la memoria y al discurso (o, mejor dicho, a los discursos) como pivotes del libro.

La obra está dividida en seis capítulos a través de los cuales se van desplegando los interrogantes iniciales y profundizando los distintos aspectos referidos a las memorias castrenses del pasado reciente, apelando a la metodología señalada anteriormente.

Así, el primer capítulo inaugura el tratamiento de "la memoria institucional del ejército sobre la represión ilegal" (pág. 29), en el marco de la noción de "escenario de memoria", de Feld, a la que invoca la autora para referir a las relaciones entre memoria y representación. La preocupación de Salvi en este punto es que, si bien las memorias institucionales del ejército están lo suficientemente constituidas e institucionalizadas, las críticas de las que ha sido sujeto 
la organización militar en las últimas décadas en la Argentina fracturaron o debilitaron esa representación. A partir de allí, lo que intenta hacer es analizar los procesos de reconfiguración de esa memoria. Estos asuntos implican actitudes de "credibilidad", "aceptación" y "organización", ejes que se despliegan en el desarrollo de todo el capítulo. El fundamento básico consiste, entonces, en dar cuenta de las transformaciones y continuidades en los discursos de los máximos referentes del Ejército Argentino en diferentes momentos clave, que para la autora se pueden circunscribir a los años 1983, 1995, 2000 y 2003, en coincidencia con un cambio de marcos políticos a nivel nacional. En este sentido, se puede argumentar, siguiendo la interpretación propuesta, que existen modificaciones de la memoria castrense que van desde un discurso triunfalista y de denegación de la violencia ilegal, encarnado en el Documento Final de la Junta Militar sobre la Guerra contra la Subversión y el Terrorismo, emitido en 1983, a la desinstitucionalización de la memoria de la "lucha contra la subversión", durante la conducción del general Bendini (alineado a la política de memoria del presidente Néstor Kichner), pasando por instancias de revisión y autocrítica respecto del rol de las fuerzas armadas durante la última dictadura militar, articulados en el Mensaje al País del general Martín Balza (que ocupó la cúpula militar durante los gobiernos de Carlos Menem), y por una reivindicación de las "víctimas militares" de la guerra antisubversiva y "fratricida", propias de la consigna Memoria Completa que hizo pública el jefe del ejército Ricardo Brinzoni (1999-2003).

De esta forma, en el análisis de Salvi de este capítulo inicial es pasible ver un movimiento pendular de la narrativa castrense que oscila entre momentos de continuidad, en cuanto a un discurso que reivindica la retórica de la guerra, la defensa de la patria contra la acción terrorista, y que se parapeta en la violencia represiva ilegal como modo de justificar esta guerra "no deseada pero inevitable frente a la agresión subversiva" (pág. 70); de discontinuidad, con el reconocimiento público por parte de algunos cuadros del ejército de prácticas de tortura y desaparición de personas, y de clara ruptura, a través de procedimientos de desplazamiento y despolitización del pasado reciente de la memoria del ejército, con una reorientación hacia épocas más ilustres y menos comprometidas (como por ejemplo, la puesta en valor del rol industrialista del ejército, y la jerarquización de insignes figuras históricas de la institución).

El segundo capítulo resulta revelador porque intenta dar cuenta de la memoria de los oficiales retirados (contemporáneos a los sucesos "recordados"), a través del análisis de las prácticas conmemorativas que "escenifican los conflictos" que la oficialidad retirada y en actividad tienen con las actuales autoridades del ejército. Sobresale en este punto la cuestión de la victimización o la figura de las "víctimas militares", surgida a mediados de los años noventa, como contraparte de la memoria de desaparecidos y de las organizaciones de derechos humanos.

El tópico del tercer capítulo ronda las tensiones intersubjetivas: a los sujetos de la experiencia se los contrapone con los sujetos de las palabras, conformando así ese caleidoscopio de sentidos, recuerdos, relatos y apropiaciones. En cierta forma, es posible observar en este apartado cómo lo vivido por una generación se hace propio, señalando huellas y tendencias, y de qué manera esto se reproduce a través del modo biográfico.

Este capítulo tiene singular importancia, puesto que, creemos, es el nudo del libro, su centro de gravedad, de allí sale su título, las “...diversas voces enmascaradas que decían ser héroes, combatientes, vengadores, vencedores y víctimas (...) su construcción narrativa: los modos de nombrar(se) en el relato, la capacidad de hacerse creer, el punto de vista, lo dejado en la sombra..." (pág. 110). Y qué sutiles expresiones para nombrar lo innombrable, para decir lo que no se ha dicho aún sobre los relatos de los "elegidos", para historizar estas memorias 
atravesadas por "mecanismos sociales y colectivos", que no existen ni solas ni aisladas, como bien da cuenta la autora, y de allí la importancia de recuperar los procesos de apropiación, rememoración y transmisión.

El cuarto capítulo, como una proyección de lo referido en el punto anterior, remite al análisis de las acciones de las agrupaciones de Memoria Completa para instalar una narrativa que caiga bien a la sociedad civil argentina. De esta forma, Salvi observa un cambio de estrategias (o en todo caso, de escenarios) de actos y prácticas conmemorativas de estos grupos: del círculo privado se pasa al espacio público. En este trasvase discursivo, lo que resulta es "la construcción de una memoria especular y reactiva que se refleja y también se contrapone a la memoria de los desaparecidos y a la lucha de los organismos de derechos humanos" (pág. 154). Una suerte de revancha respecto de las representaciones propias de los organismos de derechos humanos y tribunales civiles, que calaron hondo en la sociedad argentina de los noventa y que para los grupos de Memoria Completa, hay que neutralizar, o sumarlas a su propio discurso.

Finalmente, los últimos capítulos (el quinto y el sexto respectivamente), permiten cerrar algunas de las cuestiones planteadas en los tres primeros apartados. Se ocupan de la "dimensión del futuro que atraviesa la memoria de los oficiales retirados del ejército y de las agrupaciones de Memoria Completa" (pág. 180) y de cómo ésta es transmitida a través de la persistencia de imágenes, lenguajes y simbologías -que vehiculizaron en su momento la criminalización de la fuerza-, y su resignificación permanente en el tiempo presente. Se destaca así la recurrencia en el discurso memorialístico a los "dos lados" (o dos bandos: el del "combatiente" y el del "subversivo"), a la "guerra fratricida", a la necesidad del reparto de responsabilidades, y por ello, la idea del "perdón mutuo", atendiendo a una deuda colectiva, de la que todos son responsables, como una amalgama sin distinciones. Este posicionamiento no es inocuo. Conlleva una suerte de desplazamiento, subordinación (¿consciente?) de los compromisos que le caben a los represores en la dictadura. Entonces, las repercusiones de estas miradas en las nuevas generaciones de militares y hacia el futuro de las fuerzas armadas son complejas y quedan en continua tensión. Por un lado, se intenta "cerrar el pasado", o que "pase cerrado a las nuevas generaciones", pero sin deslegitimarlo ni cuestionarlo completamente.

Como muestra de estas resistencias, de estos sentidos contrariados, de estas reconfiguraciones permanentes en la memoria castrense, que tan bien logra analizar Salvi en este libro, vale señalar un ejemplo que excede el recorte temporal trabajado por la autora (que llega hasta 2011/2012), pero que ilustra su objeto de estudio y nos sirve para cerrar esta reseña.

El 17 de mayo de 2013 muere en prisión Jorge Rafaela Videla, uno de los máximos representantes del proceso represivo en Argentina. De los pocos avisos fúnebres aparecidos en un reconocido diario de tirada nacional, aparecen frases como las siguientes:

"Comandó la guerra interna revolucionaria contra el terrorismo subversivo apátrida. Murió en injusto cautiverio, que su muerte sirva a la verdad, la justicia y la paz entre argentinos."

“...injustamente privado de su libertad, pidiendo a Dios recompense a él y su familia por los sufrimientos padecidos."

"Familia Castrense ruega por su alma, agradeciéndole la protección de nuestras vidas."

“...despiden con dolor al expresidente." 
“...despido a quien asumió con coraje grandes responsabilidades y sirvió al país con graves riesgos.”

"La promoción del 81 del Colegio militar despide a su querido oficial instructor, 19481951, con cariño y respeto."

Está claro quiénes son los emisores de estos avisos, cuáles son sus mensajes y hacia quiénes pueden estar dirigidos. Lo que resta pensar es si estas expresiones no son más que fracturas, deslices de un relato que tiene cada vez menos oyentes, significados vacíos de algunas memorias que se han transfigurado en estos últimos treinta años, que han mutado de sentido, $y$ que han trocado a los que alguna vez se pensaron como vencedores en víctimas.

Las formas y el resultado de esta trasposición están reflejados en el libro de Salvi. Por ello, su lectura puede resultar esclarecedora, ya que revela fuentes e interpretaciones novedosas dentro de los estudios de las narrativas castrenses en la Argentina. 